\title{
The Seismic Coat: A Sustainable and Integrated Approach to the Retrofit of Existing Buildings
}

\author{
Grazia Lombardo
}

check for

updates

Citation: Lombardo, G. The Seismic Coat: A Sustainable and Integrated Approach to the Retrofit of Existing Buildings. Sustainability 2021, 13, 6466 https://doi.org/10.3390/su13116466

Academic Editor: Marc A. Rosen

Received: 1 March 2021

Accepted: 25 May 2021

Published: 7 June 2021

Publisher's Note: MDPI stays neutral with regard to jurisdictional claims in published maps and institutional affiliations.

Copyright: (C) 2021 by the author. Licensee MDPI, Basel, Switzerland. This article is an open access article distributed under the terms and conditions of the Creative Commons Attribution (CC BY) license (https:/ / creativecommons.org/licenses/by/ $4.0 /)$.
Department of Civil Engineering and Architecture, University of Catania, 95125 Catania, Italy; grazia.lombardo@unict.it

\begin{abstract}
Within the EU's environmental policy, redevelopment strategies must be designed by adopting an integrated approach. This approach considers energy savings in buildings and seismic safety as driving forces of economic growth. The recent technological evolution experienced by the construction sector has aimed to define a new building element, the seismic coat. This term refers to a structural "skin" that improves both the seismic safety and the energy efficiency of existing buildings according to standards identified by current regulations. With this regard, research was started with the aim of defining a sustainable seismic coat consisting of dry-assembled panels of natural stone blocks that are prestressed with the use of steel reinforcements. The experimentation carried out on the panel so far has shown significant results as the test building improved in terms of energy savings, seismic safety, sustainability, functionality, and aesthetic quality. By taking a case study of a 1960s building as reference, this paper highlights the findings obtained by the feasibility study of the panel, with a special focus on its technical and construction aspects, and to facilitate its manufacture with the use of industrialized processes. Furthermore, this research provides the installation procedures for the panel components and all relevant details regarding the connections with the existing structure of the building.
\end{abstract}

Keywords: seismic coat; building rehabilitation; sustainable retrofit; energy saving; seismic safety; natural stone; prestressed blocks; dry-assembled

\section{Introduction}

In recent years, the issue of rehabilitation has become significant for the current poor performance quality of most of the buildings built in Italy between the end of World War II and the early 1980s, which show physical degradation and functional obsolescence due to several factors.

In Catania, as well as in the rest of Italy, $70 \%$ of the existing building heritage was built before the enactment of the Law on Energy Saving (Law 373/1976) and is therefore devoid of any system aimed at containing both active and passive waste of energy, thus resulting in high energy costs to achieve optimal comfort.

Moreover, considering the frequency of earthquakes of significant intensity that have affected almost the entire Italian territory since 1974, and the high vulnerability of buildings constructed before the enforcement of the anti-seismic regulations, another important aspect is the anti-seismic upgrading of buildings.

The seismic vulnerability of buildings built before the seismic classification of the construction site, and therefore verified only for vertical loads in static regime, is very high. In order to reach the performance standards required by the current anti-seismic legislation, it is necessary to make the existing structure suitable for resisting the dynamic actions generated by seismic events.

The phenomenon of structural obsolescence has been discussed by several authors in order to determine whether or not this is a necessary condition for the demolition of an existing building [1]. In fact, maintenance and renovation operations can extend the 
useful life of a building by delaying the time of its demolition [2]. From this perspective, it is observed that the rehabilitation of existing buildings proves to be a more cost-effective and environmentally friendly choice than demolition and reconstruction, given the lower use of resources and less waste production [3].

Therefore, the need for seismic, energy, technological, and formal improvement is now the main consideration in prefiguring effective interventions on the existing heritage.

In the field of building rehabilitation in recent years, research in Europe has aimed at identifying the procedures and sequence of sustainable actions to be implemented for the rehabilitation of historic and modern buildings according to the construction characteristics of the existing heritage, local climate, and seismicity of the area.

Requalification strategies should be designed through an integrated and sustainable approach in which energy savings is addressed, considering an overall improvement in seismic safety, quality of life, and the aesthetic quality of a building. The approach should involve some preponderant elements of the building such as the envelope, its systems, and the integration of systems that produce energy from renewable sources, taking into account the different technological and material characteristics of the existing building on which work is being carried out [4].

Research and experimentation in the international field have focused on the building envelope.

To this end, several seismic retrofit techniques have been adopted. The insertion of elements for structural reinforcement around the external perimeter is certainly among the least invasive. In practice, these elements consist of steel or reinforced concrete bracing that are able to absorb dynamic actions when appropriately connected to the existing structure.

The recent technological evolution experienced by the construction industry aims to define a new building envelope-the seismic coat. This term means a structural "skin" that improves both the seismic safety and the energy efficiency of existing buildings according to the standards identified by the regulations in force.

Several companies in the sector have experimented and put into production a particular type of seismic coat, which completely covers the opaque envelope of the building and consists of a slab of reinforced concrete cast in place inside two layers of insulating material.

In light of the principles of environmentally sustainable development based on the desire to combine local cultural characteristics with technological innovation, the new cultural architectural process is moving towards critical reinterpretation in which there is a place for the update of traditional building systems and materials such as natural stone instead of utilizing materials currently used in construction, such as reinforced concrete and steel [5].

This paper is part of the research aimed at defining a new building envelope with high seismic and energy performance that uses materials and technologies with low environmental impact.

With regard to this problem, a research project was launched at the Department of Civil Engineering and Architecture of Catania University a few years ago, with the aim of defining a construction system for wall panels. This new construction system intends to recover the most archaic use of natural stone, i.e., the tectonic and structural use and other qualities that justify its increasing use, which are its effectiveness in protecting against atmospheric agents, its mechanical strength, resistance to aggressive agents, high durability and the limited need for maintenance, hardness, and hygroscopicity [5].

The results obtained so far have highlighted that this masonry panel has excellent performance from the point of view of environmental and energy impact as well as from a mechanical point of view, comparable to commonly used elastic materials such as reinforced concrete and steel [6].

Given the considerable structural and energy capacities of this low-thickness wall panel, the objective of this research was to study the feasibility of a similar panel when thought of as a seismic coat, and subsequently added as a second skin to the existing one, or even replace it if the choice is for a more invasive intervention on the building. 
In light of the environmentally sustainable characteristics of the raw material (i.e., natural stone), the feasibility study considered the construction and installation of a stone seismic coat with low environmental impact, with the case study of a modern building used as reference. To this purpose, the prefabrication of the panel through a modular and serial production carried out industrially allows for a simpler and faster procedure at the building site. The laying of prefabricated panels would also be further simplified and quicker if carried out through the connections of the building itself, which are designed in such a way as to be completed with standardized items and without the use of mortar or cement.

\section{Materials and Methods}

\subsection{A Structural "Skin"}

The research group coordinated by Prof. Roberto Scotta from the Department of Civil Building and Environmental Engineering, University of Padua (Italy) carried out a campaign of experimental tests on full-scale samples of a seismic coat consisting of a slab of reinforced concrete cast in place inside two layers of insulating material. These tests aimed at assessing the seismic and energy improvement of the seismic coat when applied to both load-bearing masonry [7] and buildings with reinforced concrete skeleton [8]. The tests were performed at the Expin S.r.l. laboratory, a spin-off of the University of Padua.

The reinforcement system used consisted of a $4 \mathrm{~cm}$ thick EPS inner layer in contact with the support structure, a $6 \mathrm{~cm}$ thick reinforced concrete structural layer, and a $10 \mathrm{~cm}$ thick EPS outer insulation layer. The connection to the support structure at the level of the curb-reinforced concrete beam, sized to ensure adherence support and reinforcement during cyclical tests, consisted of metal connectors with a $10 \mathrm{~mm}$ diameter and a $20 \mathrm{~cm}$ pitch arranged in two parallel rows.

The connection of the bracing with the foundation was made by using anchorage bars with improved adherence, with a diameter of $16 \mathrm{~mm}$ and positioned with a pitch of $15 \mathrm{~cm}$ in order to prevent the sliding of the sample.

The tests showed that the system was effective for both types, providing greater safety to the buildings involved in the intervention. It was found that the metal connectors used, installed at the level of the summit curb, fulfilled their function, and that there was no sliding between the support structure and the reinforcement system. The installation of the seismic coat for seismic upgrading and improvement of the contextual energy efficiency of the secondary school in Falzè di Trevignano (Treviso-Italy) showed that from the structural point of view, the added bracing did not change the stresses applied by gravitational loads, which continue to weigh on the existing structures. In case of an earthquake, the new bracing system, which is more rigid than the existing frame, would absorb the entire horizontal thrust [9]. In fact, the new seismic bracing structures were sized to fully absorb the seismic action, downgrading the existing structures to a "secondary" role.

In light of the principles of environmentally sustainable development, and based on the desire to combine local cultural characteristics with the potential of technological innovation [5], the paper studied the possibility of creating this seismic coat by replacing reinforced concrete panels with natural stone wall panels.

Therefore, the data obtained from previous research regarding the environmental, mechanical, and energy characteristics of the natural stone wall panel are reported in the following sections.

\subsection{Natural Stone}

Given the remarkable structural capabilities of natural stone, this material is recognized as having other qualities that justify its increasing use, which are its effectiveness in protecting against atmospheric agents, mechanical strength, resistance to aggressive agents, high durability and the limited need for maintenance, hardness, and hygroscopicity.

These characteristics, together with its particular aesthetic quality, make natural stone an ideal material for any type of use, both outside and inside the building. 
The use of this material in architecture is also supported by the technological evolution that has occurred in recent years, which has significantly changed the system of processing natural stone from quarrying to the finished product. Through the introduction of integrated systems and numerical control machines, it is possible to quickly and cheaply process and cut blocks of stone with very high precision.

\subsection{Environmental Impact}

Environmental impact problems concern both energy consumption in the life cycle of the building, for conditioning and maintenance, and energy consumption during construction in terms of raw materials and production energy, which represents the energy used to transform raw materials into construction materials [10].

Assessing the environmental impact of building materials is difficult because each element is intrinsically linked to the life cycle of the entire building [11].

In order to make an informed choice about building materials, some guidelines can be followed [12]:

- Use local materials, which do not require long-distance and expensive transportation;

- Choose materials based on their lifespan;

- $\quad$ Prefer recycled or recyclable materials;

- Design with the possibility of de-construction at the end of the building's life cycle in mind by reusing as much demolition materials as possible.

The stone, in this case the Etnean basalt, is easily available on site and processed in a natural way. Recent research has shown that the amount of Etna basalt naturally produced by the volcano is approximately $800,000 \mathrm{~m}^{3}$ every year [13].

Lavagna compares the embodied energy of different envelope solutions based on data published by Hammond, Jones, 2006, which report the unit of embodied energy values for different building materials, expressed in MJ/kg [14]:

- $\quad$ Local Stone 0.4;

- Mortar 1.3;

- $\quad$ Reinforced Concrete 2.6;

- Plasterboard 2.7;

- Bricks 3;

- Cellulose Insulation 3.3;

- Concrete Blocks 3.5;

- $\quad$ Rock Wool Insulation 16.8;

- $\quad$ Wood Fiber Insulation 20;

- $\quad$ Glass Wool Insulation 28;

- PVC 77.2;

- $\quad$ EPS 88.6.

Natural stone has a low embodied energy value, not only because of its natural origin but also because the stone-working does not generate waste that must be taken to the landfill. In fact, all the scraps processed can be re-utilized or used to reclaim the quarry.

Molinari provides information about the average durability in years of selected building elements and components for different countries like Belgium, France, and Hungary. The observation of these values shows that the most durable external finishes are those made of stone or exposed bricks (average of 91 years), as compared to mortar plasters (average of 35 years). Similarly, the load-bearing masonry with a longer useful life is that which is made of stone (175 years), as compared to brick masonry (98 years) [12].

Paolini pointed out that thermal insulation can have several problems of inefficiency and reliability related to the choice of materials, construction phase, and maintenance. This generates differences between the provided performance in the design phase and the real performance of masonries during the entire life of the building [15].

According to Campioli, Ferrari, and Lavagna [16], external insulation must be replaced approximately every 25 years in order to maintain the required performances. The values 
of embodied energy for brick masonry construction with thermal insulation in a time span of 100 years are almost double due to the values of embodied energy for maintenance interventions, which involve the replacement of the thermal insulation and the rebuilding of finishes scheduled every 25 years [17].

Results show that the embodied energy values depend very much on the durability of the materials utilized. In fact, a natural stone panel has a shelf life of 175 years without any maintenance [12].

In the past, the recycling of building products, especially of natural stone, was very common. In fact, many Italian monuments were built with blocks of recycled stone, such as Saint Mark's Basilica in Venice. During the Renaissance, the Roman Forum was used as a "quarry" to build new palaces. In Catania (Sicily), for example, the medieval walls of the city were built using blocks of basalt from the Roman amphitheater. Later, in 1693, the same blocks of basalt were used to rebuild the palaces destroyed by the earthquake [5].

At present, the only building material historically confirmed to be recyclable is natural stone.

\subsection{Reinforced Masonry}

With regard to this problem, at the Department of Civil Engineering and Architecture of Catania University a few years ago a research project was launched with the aim of defining a construction system for wall panels, which intends to recover the most archaic use of natural stone, i.e., the tectonic and structural use, updated with new instances applied to the technology of reinforced load-bearing masonry [5]. The construction procedure is of the integral type with modular components, and it is aimed at building load-bearing masonry panels. According to the required performances, it should be possible to insert steel bars into these panels for the vertical and horizontal reinforcement, in their diffused or concentrated versions. This is to ensure the absorption of the tensile and shear stresses induced by seismic actions, and to give the masonry structure the required ductility.

The analysis of the structural behavior on the panel made with reinforced blocks of Etna lava stone allowed us to establish the values of the features that define the deformation and mechanical strength of the model. This model was then considered for the definition of the calculation parameters. The experiments were carried out on sample panels made in a 1:5 scale, at the Official Materials Testing Laboratory of the University of Catania. According to the data reported in Table 1, the compression tests show that the values of the characteristic resistance are higher than the values allowed by the standard [6].

Table 1. Mechanical characteristics of reinforced masonry blocks of Etna basalt.

\begin{tabular}{|c|c|c|c|c|c|c|c|c|c|c|c|}
\hline Material & $\begin{array}{l}\mathrm{fb}, \mathrm{k} \\
\mathrm{MPa}\end{array}$ & $\begin{array}{l}\mathbf{f 1 b}, \mathbf{k} \\
\mathrm{MPa}\end{array}$ & Mi & $\begin{array}{c}\mathrm{E} \\
\mathrm{MPa}\end{array}$ & $\begin{array}{c}\mathrm{G} \\
\mathrm{MPa}\end{array}$ & dutt. & $\begin{array}{c}\gamma \\
\mathrm{MPa}\end{array}$ & $\begin{array}{c}\mathbf{f k} \\
\mathrm{MPa}\end{array}$ & $\begin{array}{l}\text { fvko } \\
\text { MPa }\end{array}$ & $\begin{array}{l}\mathrm{fk}, \mathrm{tab} \\
\mathrm{MPa}\end{array}$ & $\begin{array}{c}\text { fvko,tab } \\
\text { MPa }\end{array}$ \\
\hline Basalt & 150 & 130 & 1 & 60,000 & 24,000 & 9.9 & 270 & 60 & 1 & 14 & 0 \\
\hline
\end{tabular}

Legend: $\mathrm{fb}, \mathrm{k}-\mathrm{Characteristic} \mathrm{resistance} \mathrm{of} \mathrm{the} \mathrm{material} \mathrm{in} \mathrm{the} \mathrm{orthogonal} \mathrm{direction} \mathrm{in} \mathrm{relation} \mathrm{to} \mathrm{mortar} \mathrm{deposition;} \mathrm{f1b,k-Characteristic}$ resistance of the material in the parallel direction in relation to mortar deposition; E-Young's modulus of mortar; G-Transversal elasticity modulus; dutt.-Ductility of masonry; $\gamma$-Weight density of the masonry; fk-Experimental resistance of masonry to compressive stress; fvko-Experimental resistance of masonry to cutting, without compressive stress; fk,tab-Compressive resistance of masonry calculated using standard tables; fvko,tab-Cutting resistance of the masonry calculated using standard tables in absence of compressive stress.

The behavior of the diagonal collapse (Figure 1a), which allows us to define the strength referred to horizontal stresses, is very different between reinforced masonry panels and the traditional unreinforced panels. In fact, in unreinforced panels, breakage is common and occurs in the mortar layers; however, the increase of the cracking state is progressive in reinforced panels as a result of the clamping mechanisms between the basalt blocks and the steel bars. In summary, we can conclude that the proposed construction system is well suited for use in seismic areas due to the ductility requirement. 


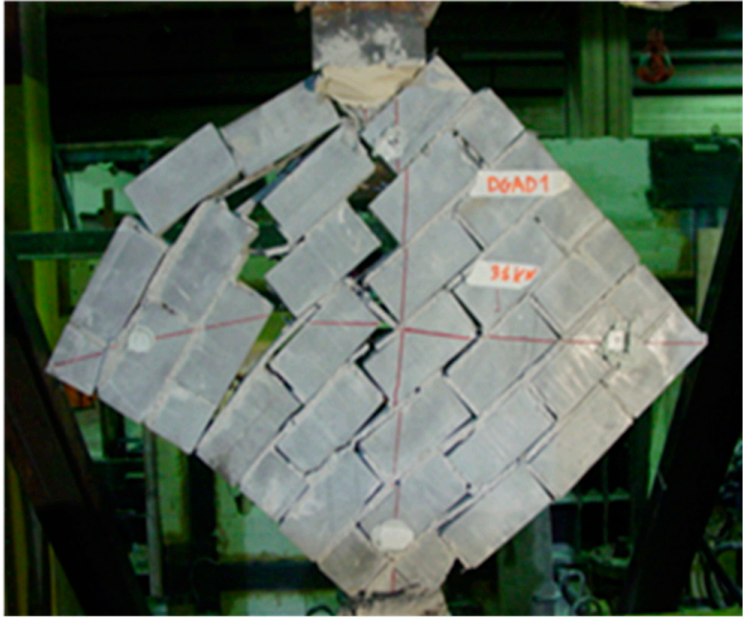

(a)

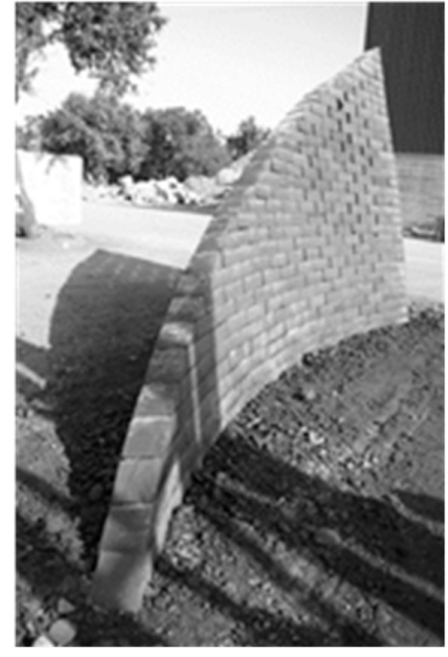

(b)

Figure 1. (a) Reinforced panel, diagonal compression test, at failure. (b) Full-scale prototype of the prestressed panel, embedded at the base.

Given the high strength of the blocks, it was possible to carry out a pre-tensioning action on the reinforcements, further improving the performance of the panel.

In order to evaluate this improvement, the strength characteristics of the masonry panels were calculated through comparisons between unreinforced masonry, reinforced masonry panels, and prestressed masonry panels constructed with basalt blocks (Table 2).

Table 2. Seismic tests of panel $(s=24 \mathrm{~cm})$ for plain collapse.

\begin{tabular}{|c|c|c|c|c|c|c|c|c|c|c|}
\hline \multirow[b]{2}{*}{$\begin{array}{l}\text { Height h } \\
{[\mathrm{m}]}\end{array}$} & \multirow[b]{2}{*}{$\chi \mathbf{s}=\mathbf{h} / \mathbf{s}$} & \multirow[b]{2}{*}{$\begin{array}{c}\text { Seism. } \\
\text { Force Fs } \\
{[\mathrm{kN}]}\end{array}$} & \multicolumn{2}{|c|}{ Ord. Mas. $P=0 \mathrm{kN}$} & \multicolumn{2}{|c|}{ Reinf. Mas. $p=0 \mathrm{kN}$} & \multicolumn{2}{|c|}{ Reinf. Mas. $p=1000 \mathrm{kN}$} & \multicolumn{2}{|c|}{ Reinf. Mas. $p=2000 \mathrm{kN}$} \\
\hline & & & $\begin{array}{c}\text { Collap. } \\
\text { Force } F_{x R} \\
{[k N]}\end{array}$ & $\begin{array}{l}\text { Saf. Fac. } \\
T_{x R} / F s\end{array}$ & $\begin{array}{l}\text { Collap. } \\
\text { Force } F_{x R} \\
{[k N]}\end{array}$ & $\begin{array}{l}\text { Saf. Fac. } \\
T_{x R} / F s\end{array}$ & $\begin{array}{c}\text { Collap. } \\
\text { Force } F_{x R} \\
{[k N]}\end{array}$ & $\begin{array}{l}\text { Saf. Fac. } \\
\mathrm{T}_{\mathrm{xR}} / \mathrm{Fs}\end{array}$ & $\begin{array}{l}\text { Collap. } \\
\text { Force } F_{x R} \\
{[k N]}\end{array}$ & $\begin{array}{c}\text { Saf. Fac. } \\
T_{x R} / F s\end{array}$ \\
\hline 3.50 & 14.58 & 4.253 & 4.633 & 1.09 & 24.382 & 5.73 & 132.313 & 31.11 & 172.855 & 40.65 \\
\hline 9.00 & 37.50 & 10.935 & 3.735 & 0.34 & 11.239 & 1.03 & 52.346 & 4.79 & 67.322 & 6.16 \\
\hline 20.00 & 83.33 & 24.300 & 3.376 & 0.14 & 6.639 & 0.27 & 24.358 & 1.00 & 30.386 & 1.25 \\
\hline 22.00 & 91.67 & 26.730 & 3.344 & 0.13 & 6.297 & 0.24 & 22.276 & 0.83 & 27.615 & 1.03 \\
\hline
\end{tabular}

Seismic testing of a $24 \mathrm{~cm}$ thick panel for in-plane collapse was repeated, using two different values of the prestressing action: $p=1000 \mathrm{kN}$ and $p=2000 \mathrm{kN}$ [6].

Taking into account the equilibrium conditions, the horizontal force was calculated, showing that the collapse occurs only due to the in-plane and out-of-plane bending action, and not due to the shear action.

The same procedure was repeated for the different values of panel height and thickness, for different loading conditions and shape. The safety factor was subsequently calculated. The case of in-plane failure tests of a masonry panel with the following geometric characteristics was considered: base $b=100 \mathrm{~cm}$; thickness $s=24 \mathrm{~cm}$; variable height $\mathrm{h}$. The maximum value of the prestressing action for this panel was 200 ton. The tests were repeated using two different values of the prestressing action: $p=1000 \mathrm{kN}$ and $p=2000 \mathrm{kN}$ of the critical load in both in-plane and out-of-plane. The combined testing of compressive and bending action conditions and the in-plane shear action was performed, considering the safeguarding limit of the life state according to the safety tests included in NTC 2018.

Table 2 shows the trend of the force that leads to the failure of the masonry panel and the safety factor. The safety factor was calculated as the ratio between the breaking force and the seismic action. It was calculated for different values of height, slenderness, and pre-tensioning action. Furthermore, Table 2 shows that the pre-tensioning action highly improves the performance of the masonry to resist horizontal actions. 
In the case of thickness, $s=24 \mathrm{~cm}$, the normal masonry panel performed up to $3.5 \mathrm{~m}$ in height (according to the seismic test), while the reinforced masonry performed up to $20 \mathrm{~m}$ with pre-tensioning action of 100 ton, and up to $22 \mathrm{~m}$ with pre-tensioning action of 200 ton. The panel performance was better when the pre-tensioning actions were activated.

The results obtained show that the contribution of pre-tensioning actions was significant with respect to the increase of the panel thickness.

The creation of a full-scale prototype with blocks of prestressed Etna lava stone confirmed the theoretical results obtained from the simulations [18].

This prototype consisted of a curved wall panel, inclined by 10 degrees, with a thickness of $20 \mathrm{~cm}$ and a height of $3.5 \mathrm{~m}$ at the highest point (Figure 1b). The panel was embedded at the base, free on the other sides, and showed conditions of perfect equilibrium.

The experiment showed that the state of pre-compression due to the reinforcement inside the blocks led the masonry panel to resist bending and traction stresses, which would otherwise be impossible.

Therefore, in conclusion, we can say that panels of Etna basalt blocks assembled dry and prestressed, even with small thicknesses, ensure a remarkable behavior and resistance to seismic actions typical of elastic materials such as steel and reinforced concrete.

\subsection{Building Envelope and Energy Consumption}

For an environmentally sustainable building, technological innovation is currently oriented towards investigating and improving the relation between envelope and energy [19].

From the energy point of view, various studies have already been started on the modern building heritage, which is a large part of the existing heritage worldwide. This heritage is generally characterized by envelopes with poor performance under the environmental and energy aspects [20].

Initial research has shown that for buildings made with massive envelopes, the primary energy requirement-for both winter and summer air conditioning-is generally lower than those made with light envelopes [21].

In fact, it appears that by virtue of their high thermal inertia, massive envelopes ensure better results in those climatic areas characterized by wide daily temperature ranges. Finally, thermal insulation has proven to be of secondary importance when it is coupled with massive envelopes [22].

At the Department of Civil Engineering and Architecture of Catania University in particular, these studies aimed to identify guidelines for optimizing the energy retrofit intervention of the building heritage belonging to the so-called "Mediterranean" GeoCluster.

With reference to a simple building (elementary cell) located in an area characterized by the Mediterranean climate (Eastern Sicily), research dedicated to a number of simulations optimizing the requirements of the thermophysical nature of the building envelope has already been started. Its purpose is to obtain maximum reductions in energy consumption for the conditioning of indoor areas [13].

The relationship between envelope and energy, through the connection of thermal mass (in terms of thermal capacity $\mathrm{kJ} / \mathrm{m}^{2} \mathrm{~K}$ ) and thermal insulation (in terms of thermal resistance $\mathrm{m}^{2} \mathrm{~K} / \mathrm{W}$ ) of the envelopes has been studied with simulations in the dynamic regime, and in the different materials most commonly used in buildings.

The results obtained from the envelope showed that in a Mediterranean climate, characterized by significant temperature changes, there is no combination of thermal mass and envelope insulation that generates good performance in both winter and summer.

In fact, as the thickness of the insulation increased, it was possible to observe that winter performance improved while summer performance worsened.

On the other hand, when the thermal mass increased, it was possible to observe that the summer performance improved. The spectrum of solutions identified allowed us to optimize the relationship between mass of accumulation-insulation for the purpose of overall energy savings for the air conditioning of environments, both in the case of thin and light envelopes, and in the case of envelopes characterized by higher thicknesses. 
Table 3 below shows the possible envelope solutions. It can be observed that when the thermal capacity varied and was identified in correspondence with the optimal resistance values, the lowest Primary Energy Requirement (PER) were produced [13].

Table 3. Possible envelope solutions.

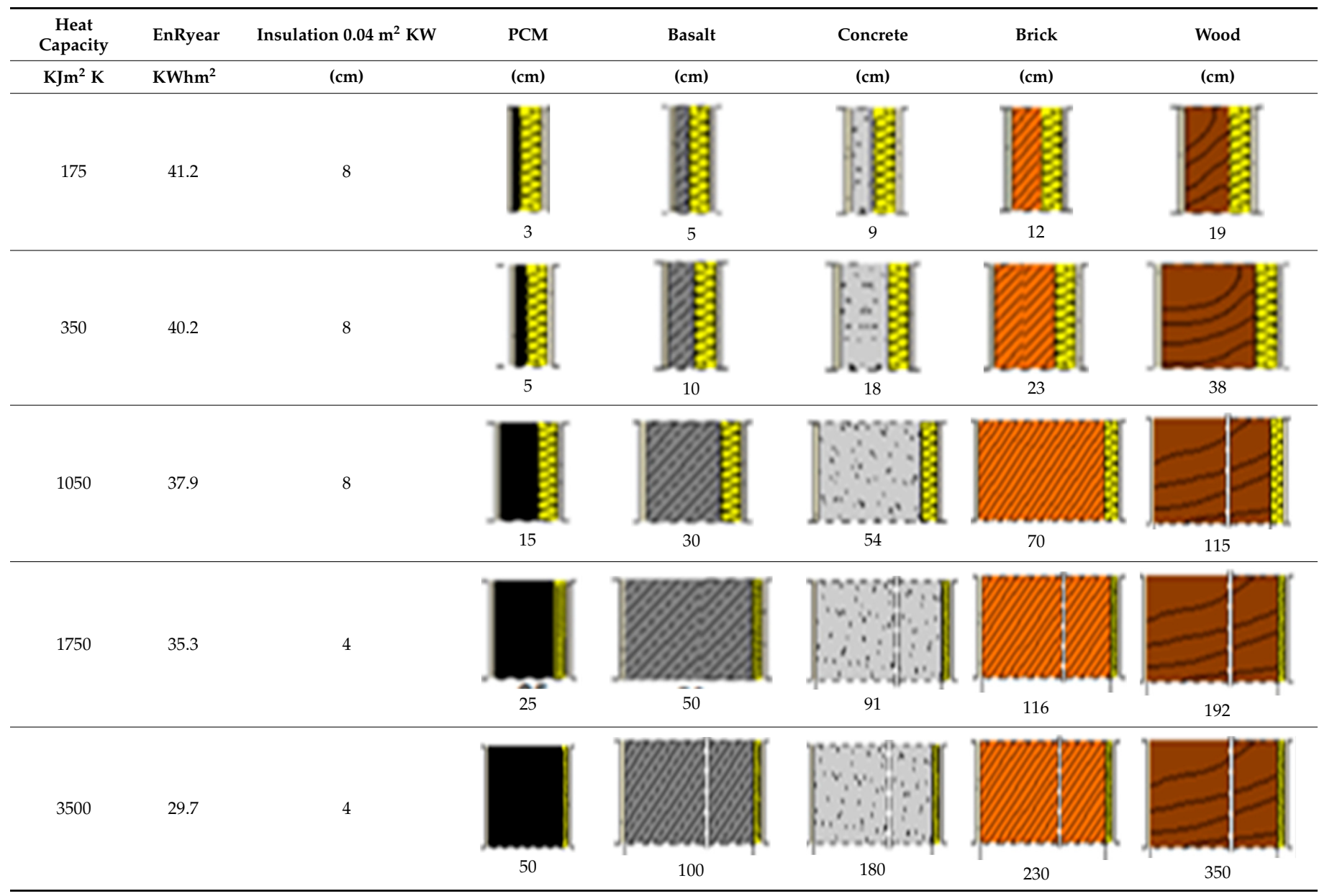

By virtue of the fact that the increase of the thermal capacity in both summer and winter always guarantees better energy performance, the envelopes made with materials characterized by a high inertia have smaller thicknesses at the same energy performance. As shown in Table 3, the thinnest are always the envelopes made with PCM, which is still in a state of refinement, and so not widely used in construction.

Confirming the research previously carried out, results for the following materials are presented: envelopes of Etna basalt, concrete baffles, brick blocks, and wood.

These observations led us to rethink the use of materials, which belong to the building tradition such as natural stone.

These materials have shown that through high thermal capacity and even with modest thicknesses (starting at $5 \mathrm{~cm}$ ), if coupled with insulating materials according to precise sizing, their energy performance would not only be competitive but also better than other materials widely used in construction, such as brick and concrete.

In summary, the seismic coat made with EPS panels and reinforced concrete tested by the University of Padua and used in several energy and structural retrofit interventions showed that the system is effective, and that the connections prevent sliding between the support structure and the reinforcement system, thus improving energy performance and giving greater structural safety to the buildings included in the intervention $[7,8]$.

The test phase was carried out by the Department of Civil Engineering and Architecture of Catania University, through simulations, laboratory tests, and the creation of 
a full-scale prototype (Figure 1). It showed the remarkable resistance of prestressed reinforced masonry panels with blocks of Etna natural stone to bending and shear stress, even with greatly reduced thicknesses $(20 \mathrm{~cm})$. It also showed a typical behavior of elastic materials, such as steel and reinforced concrete, in response to seismic actions (Table 2). Therefore, this panel can be a valid bracing action, capable of converting an existing building with a load-bearing skeleton into an anti-seismic one, made in the absence of anti-seismic requirements and sized only to vertical actions, such as the bracing of reinforced concrete panels currently manufactured. From the energy point of view, the experimental phase of the research showed that the prestressed masonry panel of natural stone, even with small thicknesses, combined with an adequate layer of thermal insulation, provide excellent thermodynamic performance when used for building envelopes in areas with a Mediterranean climate as compared to other popular building materials such as brick and concrete. This comes as a result of high thermal inertia. In fact, the high density of Etna stone with good phase shift and attenuation values provides good summer comfort, thus reducing the discomfort due to the high thermal shock typical of the Mediterranean climate.

In summary, the envelope of a building made with a panel of Etna stone, with a thickness of $10 \mathrm{~cm}$ and coupled with a natural insulator such as rock wool—which can withstand very high temperatures and is fireproof and highly draining — brings the annual primary energy demand to minimum values, ensuring good environmental comfort in different seasons. From the point of view of environmental sustainability, natural stone has a low value of embodied energy per unit $(0.4 \mathrm{MJ} / \mathrm{kg})$ as compared to reinforced concrete $(2.6 \mathrm{MJ} / \mathrm{kg})$, and similar to wood fiber insulation $(20 \mathrm{MJ} / \mathrm{kg})$ or rock wool $(16.8 \mathrm{MJ} / \mathrm{kg})$ it has a low value of embodied energy per unit as compared to EPS ( $88.6 \mathrm{MJ} / \mathrm{kg})$ [14]. For natural stone, which has high durability and a shelf life of 175 years, no maintenance is planned [12]. However, in order to maintain the required performances, external insulation must be replaced approximately every 25 years [13].

The data obtained from previous research has shown that the natural stone wall panel can be used as a seismic coat.

In the following section, the feasibility study defines all the constructive aspects of production and installation on site that allow the use of this wall panel as a seismic coat in reference to a case study.

\subsection{The Case Study}

In the last decade, the sector of new buildings in the Province of Catania lost $60 \%$ of its value, while the only growing sector was the extraordinary maintenance of existing buildings, which recorded a $20 \%$ increase in the same period owing to tax incentives and greater attention to energy saving.

From the perspective of the sustainable planning of interventions on the built environment, the renovation of individual buildings should then be framed in the more general enhancement of the city, aimed at minimizing the consumption of land, time, and energy. In this regard, a building belonging to Catania's building heritage of the 1960s, originally intended as a reception and leisure center for the recreational activities of the neighborhood, seemed to be the right choice as a case study for the application of the new retrofit system with the new seismic coat, being tested at the time of writing.

The building belongs to the parish complex "S. Giuseppe in Ognina", located in the Picanello district of Catania, an area in a state of decay and characterized mainly by nineteenth century residential buildings.

This typical building of the 1960s, with a box configuration and a reinforced concrete load-bearing skeleton, in addition to having an alienated relationship with the nineteenthcentury district it is located in, appeared in a seriously degradated condition. The recovery of an existing building, as in the case of the parish complex "S. Giuseppe in Ognina", could be the reason for launching a requalification of the whole Picanello district. Keeping the building's original purpose in mind, redesigning it according to the current standards of 
a neighborhood cultural center housed in a completely requalified building could offer a positive image of itself as a center of social aggregation in the Picanello district.

The building has a regular layout, similar to a rectangle of $30 \mathrm{~m} \times 12 \mathrm{~m}, 17.50 \mathrm{~m}$ high, with an emerging stairwell. It is composed of a load-bearing framed structure made of reinforced concrete, connected to foundation beams also of reinforced concrete; the floors are of a mixed structure of reinforced concrete and bricks; the walls are made of concrete blocks. The staircase, in an off-center position, is made of reinforced concrete.

The building was built in the 1960s, in the total absence of seismic and energy-saving regulatory requirements. Today it is seriously degradated, caused by the poor durability of the materials used, which is typical of most buildings constructed after the Second World War. Therefore, it can be representative of the modern building heritage and considered a valid case study for the testing of innovative and sustainable retrofit interventions aimed at structural and energy improvements in buildings from that period, based on the use of seismic coat made of natural stone.

\section{Results}

The feasibility study defined the following:

$\checkmark \quad$ The construction features of the new seismic stone coat;

$\checkmark \quad$ The construction of a single prefabricated panel with industrialized systems;

$\checkmark$ The methods of simplified installation on site of the panels;

$\checkmark \quad$ All types of panel connections: panel-panel, panel-existing structure, and panel-foundation.

\subsection{The New Stone Seismic Coat}

The industrialized construction process of the panel under experimentation is integral to the modular components. The process aims to construct panels of lava stone blocks, inside of which steel bars are inserted for vertical reinforcement so as to absorb traction and shear stresses induced by seismic actions and give the wall panel the required ductility.

The blocks are sized in such a way that, with only one type of base block (A) and the relative half-block (B), a high degree of flexibility and aesthetic quality can be obtained from the panel design (Figure 2).

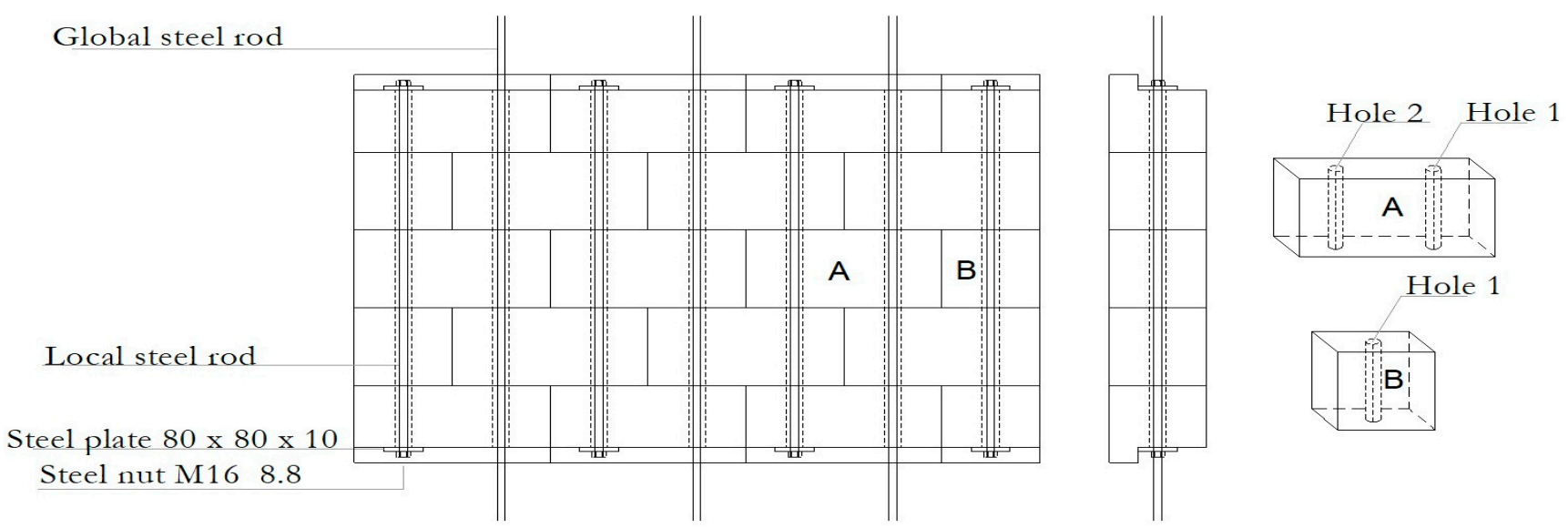

Figure 2. Reinforced panel and its blocks (type A and B).

A groove is made in correspondence to the blocks in the header, which allows the housing of the plate and the clamping nut of the panel's prestressing reinforcement to regularize the joints between the panels in the facade.

The blocks are made with a precision cut, carried out with numerically controlled machines.

The precision of these machines gives the block a perfect squaring and regular faces, ensuring perfect adherence between them, which is fundamental for the panel's water resistance and for a more uniform transmission of the prestressing load between the blocks. 
To accommodate the metal reinforcement, two cylindrical holes are drilled in the base block and one in the middle block in a barycentric position, with a diameter of $36 \mathrm{~mm}$, using a drill press.

This allows both the positioning of the blocks with staggered joints and the alignment of the holes in which to insert the prestressed reinforcement.

The double hole of the block allows the housing of a double reinforcement.

The first reinforcement (local steel rod) is used for the pre-compression of the single panel and is placed in the factory during prefabrication. The second reinforcement (global steel rod) is placed on site to give continuity to the panels, from the foundations to the top of the building. The holes are filled under pressure with resin, which allows for better adherence and also the protection of the reinforcement steel.

In the factory, the prefabrication of single panels is carried out by connecting the reinforcements housed in the first hole to the head blocks placed at the two ends of the single panel. This is performed by means of galvanized steel plates $(80 \times 10 \mathrm{~mm})$ and a nut, to which a specific tightening value is applied in order to give the necessary prestressing.

The dimensions of the blocks depend on the architectural and construction requirements of the building envelope, taking into account the position of the openings, the inter-floor height, the size of the structural mesh, etc.

Block thickness is variable, from 10 to $20 \mathrm{~cm}$.

With regard to the annual energy requirement (Table 3), research has shown that the building envelope made of lava stone panels, with a thickness of $10 \mathrm{~cm}$ and coupled with $8 \mathrm{~cm}$ of thermal insulation $\left(0.04 \mathrm{~m}^{2} \mathrm{kw}\right)$, demonstrates excellent performance in the reduction of the annual energy consumption (EnRyear $\left.=40.2 \mathrm{Kwh} / \mathrm{m}^{2}\right)$.

However, considering that in order to maintain the required performances, external insulation must be replaced approximately every 25 years. And since natural stone has high durability and a shelf life of 175 years [18], no maintenance is planned. It was preferable to prepare the thermal insulation inside and the pre-compressed stone panel outside.

Considering that the lava stone panel already has excellent thermal performance, any increase in annual Primary Energy Requirement due to the internal positioning of the insulation is negligible compared to the energy incorporated for maintenance, scheduled every 25 years, which concerns the replacement of the thermal coat and the renovation of finishes.

In the light of the tests carried out (Table 2), which have highlighted the remarkable structural capabilities of the pre-compressed Etna stone panel, it is believed that this thickness could reach up to $20 \mathrm{~cm}$ for the seismic coat, based on structural calculations. One of the techniques adopted in structural retrofit interventions consists in inserting bracing elements properly connected to the original structure, which is able to absorb the stresses induced by dynamic forces, thus reducing the vulnerability of the building up to the standards provided by the current anti-seismic regulations. Considering how the new seismic coat has been conceived, various intervention strategies can be adopted, such as having the bracing concentrated in some parts or diffused over the whole building envelope.

In the first case, the bracing panels must be concentrated and positioned flat, compatible with existing architectural constraints, in a symmetrical way and in a perimeter position, in order to reduce eccentricities between the center of mass and center of stiffness at the various elevations. The thickness of the panel, the diameter, and the pre-tensioning value of the reinforcements are sized as determined by structural calculations.

The other panels, with no structural function, have a thickness of $10 \mathrm{~cm}$ and architecturally adaptable to any formal and aesthetic solution for the facade.

Along the lines of the seismic coats already in production, the second strategy includes the use of the panel with the same thickness as the blocks, with the same pre-compression reinforcement throughout the facade, and to be adapted exclusively to the facade's architectural composition. In this case, there is a box effect and it is well suited for regular envelopes with regular openings. Both strategies can be indifferently adopted, either as a second skin of the building, keeping the original one, or as its replacement, in more invasive 
interventions as in the case study that included a full retrofit intervention with a redesign of the facade. The new seismic coat consisting of the pre-compressed prefabricated stone wall panel, coupled with thermal insulation, will be properly connected to the existing structure in correspondence to the perimeter floor beams. Consequently, the weight of the panel will not affect the existing structure, but rather transmitted to the ground through a specially made independent foundation.

\subsection{Application to the Case Study}

The case study is a building disused for some years and in a serious condition of both functional and material deterioration. Hence, the choice of a radical retrofit intervention aimed at giving back an aesthetic, formal, functional, energetic, and structural quality to this building, through the application of the new seismic coat as a new sustainable building envelope.

The bracing system concentrated in some points of the building can allow for more freedom in the organization of interior spaces and related openings, and more generally in the morphological aspects of the project. The removal of the original envelope also allows us to increase the interior spaces of the building by $60 \mathrm{~cm}$ for the whole perimeter and for all floors.

For the interior spaces, the following changes are planned: construction of new toilets on each floor, compliant with the Italian Law 13/89 on disabilities; insertion of an elevator according to Law $13 / 89$ and a freight elevator attached to the storage rooms, which must serve all floors; construction of a mezzanine on the first level, with a special metal staircase independent from the main building staircase, to accommodate the storytelling room in the children's section; demolition of partition walls, where required by the project to create larger rooms or open spaces; and renovation of flooring and interior painting (Figure 3).

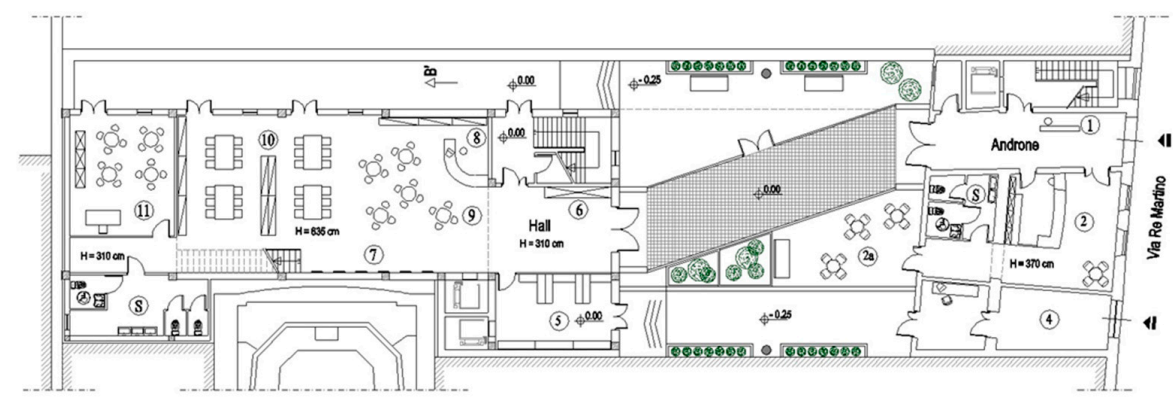

(a)

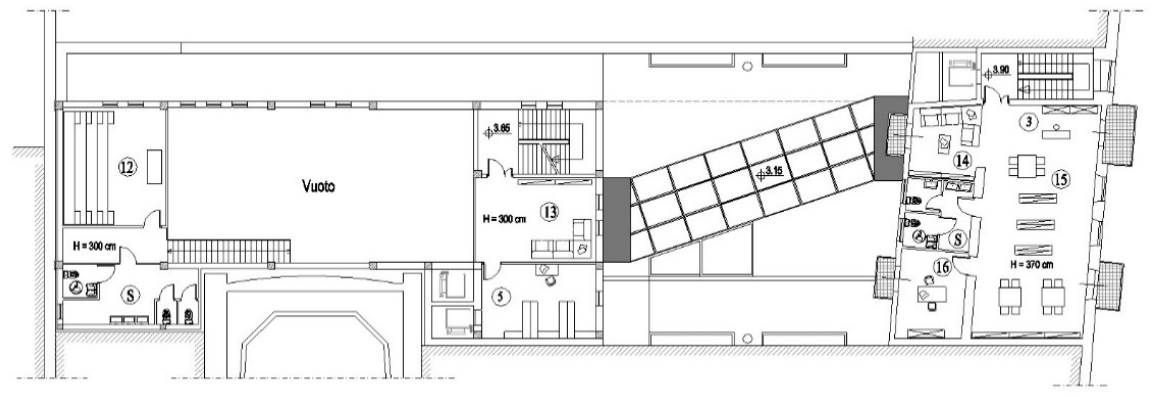

(b)

Figure 3. Layouts of the first (a) and second level (b), project.

From an aesthetic and formal point of view, the original box-shaped configuration is still intact in contrast to the nineteenth-century context of the neighborhood and is softened by the use of the basic material that has always given life to all buildings in the Etna area, i.e., lava stone. 
The design idea starts from imagining the cultural center as a neutral, compact, "lithic" box in which the outer skin, made entirely of stone, should not simply "cover" but "build" a massive picture of a monolith, with a homogeneous appearance, without exposed joints or special textures.

The only items that interrupt this "free facade" are the gaps of the windows. They are tall and narrow, almost like slits, of different heights, freely distributed and put in relation to each other in order to create rhythm in the facade.

The window frames are housed with dark metal, which are an integral part of the back window. In order to obtain the aesthetic effect of the facade entirely covered with stone, eight types of prefabricated panels have been provided (Figure 4), all consisting of a single base block $(40 \times 20 \times 10)$ and a corresponding half-block $(20 \times 20 \times 10)$.
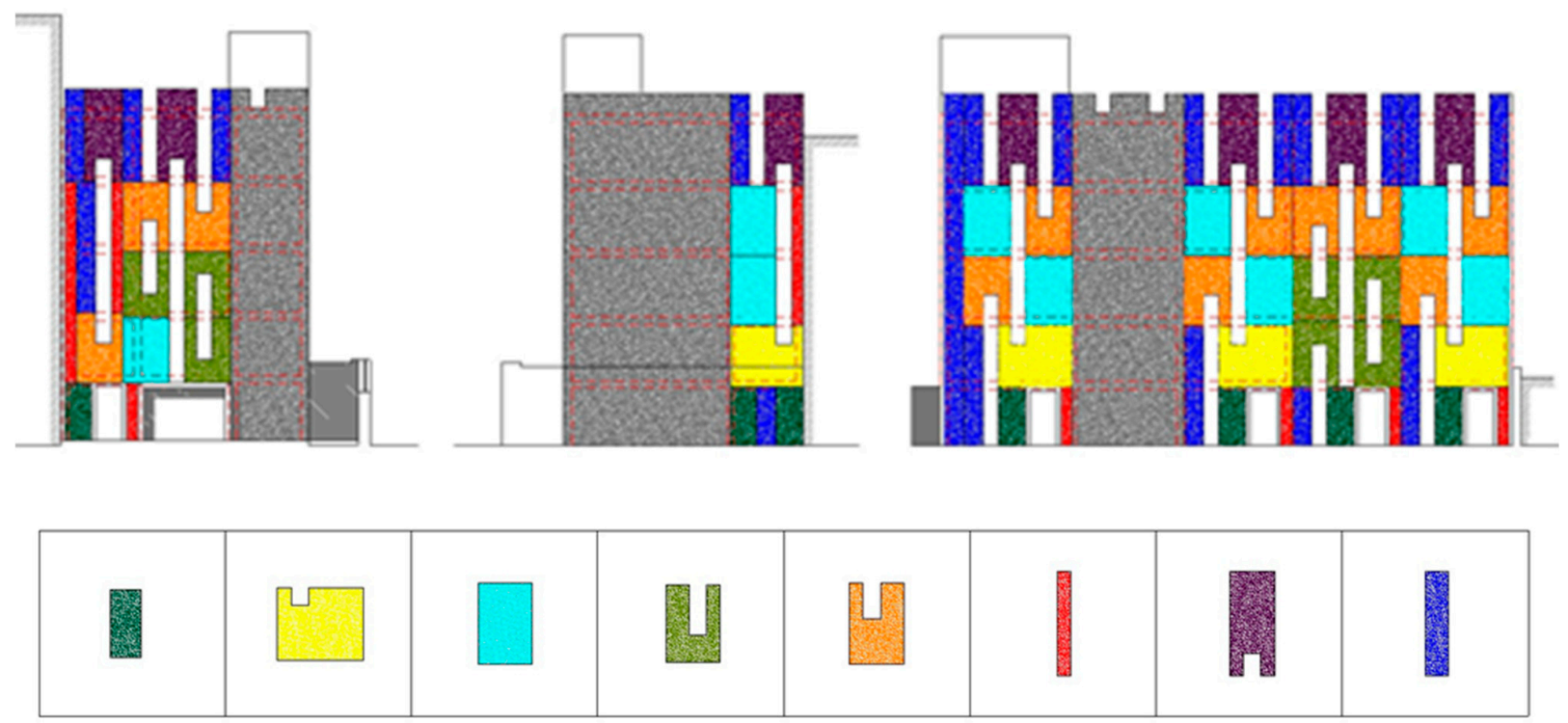

Figure 4. The facades with 8 types of panels.

Some panels have a rectangular shape, in order to fill the "full" spaces of the façade; others are shaped like a " $U$ ", more or less deep, in order to accommodate the "voids" near the frames.

The heights of the panels vary according to the heights of the building's inter-floors, since each panel, near its first and last layer of blocks, must be anchored to the existing perimeter beams. Moreover, each panel has the same external finish on both its faces, so it can be positioned in different ways.

This flexibility of arrangement has allowed us to obtain the different architectural effects of full and empty spaces on the facade, decided during design development, through a simplified prefabrication, providing only 8 types of panels.

From a structural point of view and having been built before the coming into force of the first anti-seismic regulations, the building has a high vulnerability since the resistant structures have been dimensioned to resist only vertical loads.

Therefore, the bracings are rigidly connected to the existing reinforced concrete frame and have the function of redistributing the stiffnesses in a suitable way inside the structure; in this way, the stresses induced by earthquakes are conveyed exclusively onto the bracings (Figure 5).

By positioning the bracings in five points of the structure arranged symmetrically on the layout and in a perimeter position, the purpose is to obtain a structural behavior with linear displacements, reducing torsional effects to a minimum level. Based on simulations and experiments carried out on the full-scale prototype (Figure 1), for the case study under consideration, the thickness has been assumed at $20 \mathrm{~cm}$ in the pre-dimensioning stage, 
while the prestressing condition to be applied through the bracing will have to be validated by an appropriate structural verification.

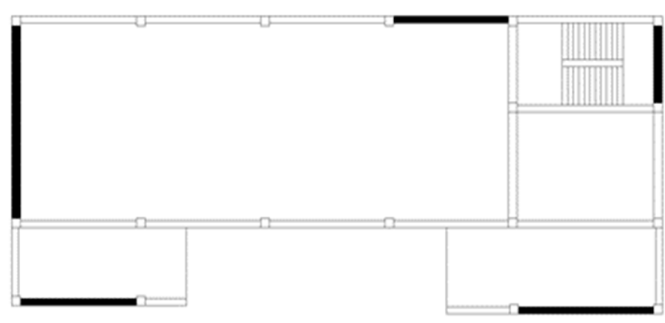

(a)
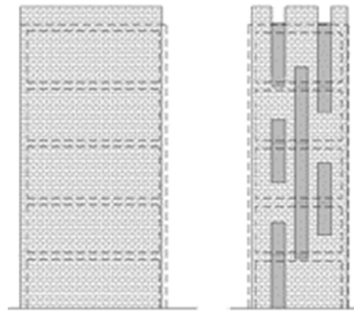
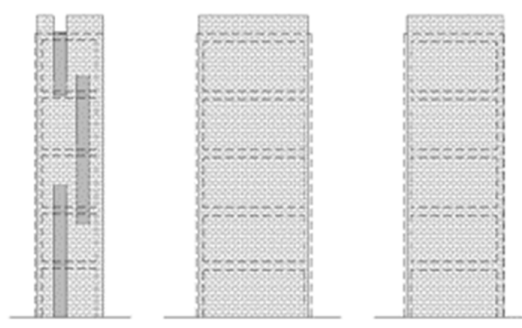

(b)

Figure 5. The five bracing panels in layout (a) and elevation (b).

In the hypothetical case of having to remove the original envelope, the $8 \mathrm{~cm}$ thick thermal insulation will be applied on a plasterboard panel made to replace the old envelope.

From the results already obtained from the research, in terms of energy requirements and thermal comfort, it is possible to observe that for a building in a Mediterranean climate the thermal performance of a $10 \mathrm{~cm}$ panel of lava stone coupled with $8 \mathrm{~cm}$ of thermal insulation $\left(0.04 \mathrm{~m}^{2} \mathrm{~K} / \mathrm{W}\right)$ guarantees a low annual Primary Energy Requirement (i.e., $40.2 \mathrm{KWh} / \mathrm{m}^{2}$ ) as compared to the most commonly used construction materials (Table 3).

From the energy point of view, in comparing the stratigraphy of the original opaque envelope (Table 4 ) to the one constituted by the new seismic coat (Table 5) and taking into account the characteristics of the Etnean basalt (Conductivity $2.1 \mathrm{~W} / \mathrm{mK}$, Mass Volume $2800 \mathrm{Kg} / \mathrm{m}^{3}$, Specific Heat $\left.1300 \mathrm{~J} / \mathrm{KgK}\right)$, there is a clear improvement.

Table 4. Opaque Vertical Closure, Project.

\begin{tabular}{cccc}
\hline Opaque Vertical Closure Actual Situation & $\mathbf{S ~ ( m )}$ & $\mathbf{C}(\mathrm{W} / \mathrm{mK})$ & $\mathbf{D}\left(\mathrm{Kg} / \mathrm{m}^{3}\right)$ \\
\hline Internal Finish & 0.02 & 0.7 & 1400 \\
Concrete Full Bricks & 0.20 & 1.1 & 180 \\
Air Chamber & 0.08 & 1.3 & 1.23 \\
Concrete Full Bricks & 0.30 & 1.1 & 180 \\
Total Thickness & & $0.60 \mathrm{~m}$ & \\
\hline
\end{tabular}

Table 5. Opaque Vertical Closure, Project.

\begin{tabular}{cccc}
\hline Opaque Vertical Closure Project & $\mathbf{S}(\mathbf{m})$ & $\mathbf{C}(\mathbf{W} / \mathbf{m K})$ & $\mathbf{D}\left(\mathbf{K g} / \mathbf{m}^{\mathbf{3}}\right)$ \\
\hline Internal Finish & 0.02 & 0.7 & 1400 \\
Plasterboard Panel & 0.013 & 0.43 & 1250 \\
Thermal Insulation & 0.08 & 0.04 & 60 \\
Air Chamber & 0.025 & 1.3 & 1.23 \\
Stone Panel & 0.10 & 2.1 & 2800 \\
Total Thickness & $0.238 \mathrm{~m}$ & & \\
\hline
\end{tabular}

In fact, it is observed that the transmittance is greatly reduced to a value of $0.322 \mathrm{~W} / \mathrm{m}^{2} \mathrm{~K}$ (more than 4 times lower than the actual situation), thus respecting the limit of the law (Table 6).

The performance quality of the envelope in summer conditions improved, going from a class V (mediocre) to a class III (average).

The overall effects of energy savings in the building on the entire envelope consisting of the new seismic coat will subsequently be calculated over the year with dynamic software.

\subsection{The Installation of the Panel and the Connections on Site}

The panels will be connected to the load-bearing structure of the building at the floor beams. They will be placed next to each other, taking into account their different 
thicknesses, so that on the whole, the entire facade shall appear as if covered by a single continuous fabric of stone.

The continuity between the panels in addition to the aesthetic effect allows us to transmit the weight of all the panels to the ground through a special foundation curb.

The system of connection between the panels and the foundation can be carried out taking into account the results obtained from test construction of the prototype in real scale (Figure 6a).

Table 6. Opaque Vertical Closures.

\begin{tabular}{cccc}
\hline Opaque Vertical Closure & Limit of Law & Actual Situation & After Intervention \\
\hline Transmittance "U" $\left(\mathrm{W} / \mathrm{m}^{2} \mathrm{~K}\right)$ & 0.41 & 1.344 & 0.322 \\
Phase Shift "S" (hours) & $>12$ & 4.35 & 9.82 \\
Attenuation "Fd" & $<0.15$ & 0.767 & 0.251 \\
Envelope summer performance & Class III & Class V & Class III \\
\hline
\end{tabular}

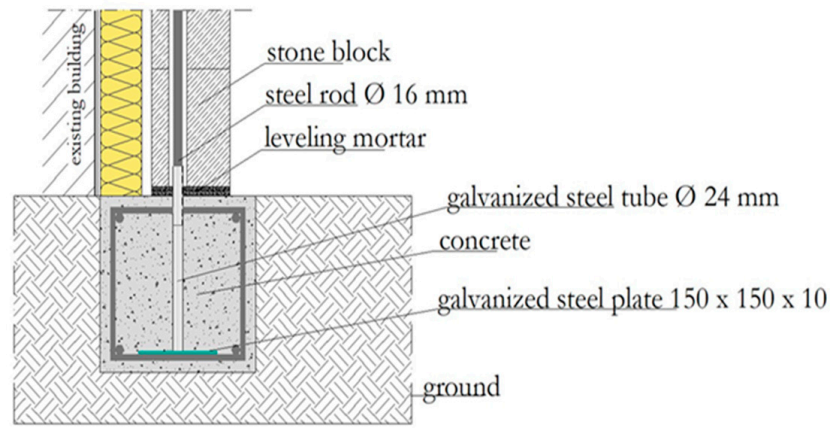

(a)

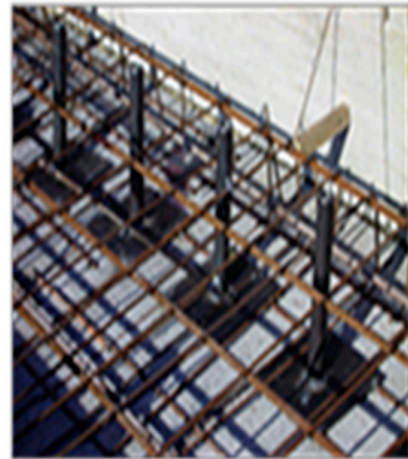

(b)

Figure 6. (a) The connection between the panel and foundation, (b) detail view.

The connection with the specially made reinforced concrete foundation is composed of various items, i.e., a galvanized steel plate $(150 \times 150 \times 10 \mathrm{~mm})$ anchored to the reinforced concrete reinforcement of the foundation, and a hollow galvanized steel cylindrical item consisting of a tubular rod (Ø 24) threaded and internally welded to the plate (Figure 7a). The plate is completely embedded inside the foundation and the tubulars protrude $5 \mathrm{~cm}$ from the top of the foundation (Figure 6a).

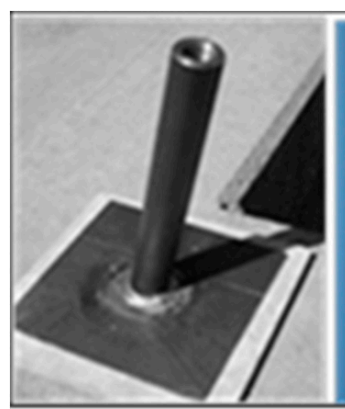

(a)

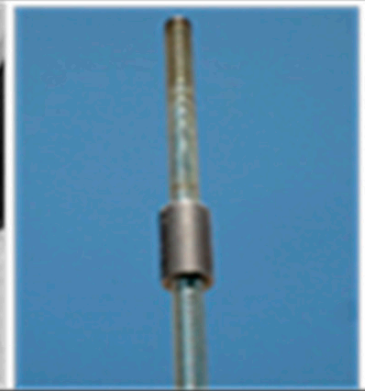

(b)

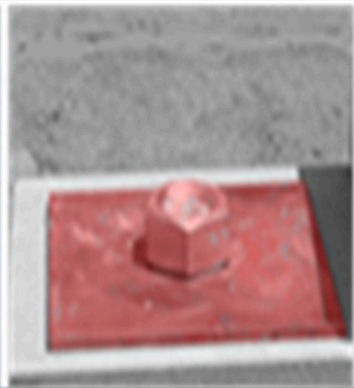

(c)

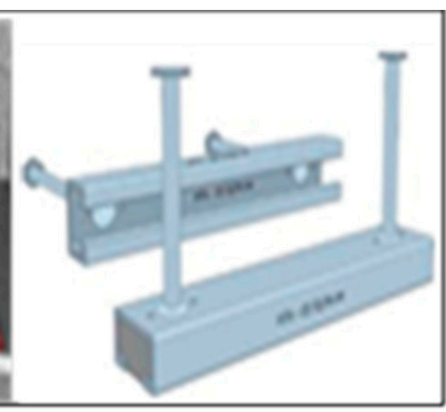

(d)

Figure 7. (a) Tubular rod welded to the plate, (b) threaded sleeve, (c) plate and pre-compression nut, (d) Halfen profile.

These are aligned with the panel at a distance of $40 \mathrm{~cm}$ so as to allow the connection between the foundation and the threaded galvanized steel bar housed in the second hole of the panel (Figure $6 \mathrm{~b}$ ).

Along these bars, the prefabricated panels are slid from top to bottom, from the first to the last floor. At the upper end of the panel, in correspondence to the floor beam, a 
threaded sleeve guarantees the connection with the panel reinforcement placed on the upper floor (Figure $7 \mathrm{~b}$ ).

At the same time, the connection with the beam of the existing structure is executed just as the University of Padua did in the testing of the reinforced concrete panel.

Standard Halfen profiles (Figure 7d) are used, with bolts and galvanized steel plates. When the panel acts as bracing, it must be bound by a rigid connection system capable of transmitting horizontal stresses.

In this case, two T-shaped welded steel plates are connected to the vertically arranged Halfen profiles. The core of the $\mathrm{T}$ is inserted between one panel and the next and has a hole corresponding to which a tube of about $24 \mathrm{~cm}$ high is welded at mid-height. This tubular rod is inserted every $40 \mathrm{~cm}$ inside the second hole of all the blocks placed at the two lower and upper ends of the panels. This connection creates continuity between the panels and the beam and guarantees the transmission of horizontal actions from the existing structure to the bracing through the appropriate dimensioning of all the metal parts forming the node (Figure 8a). Halfen profiles in production are able to transfer seismic stresses acting on the entire building to the bracing panels due to their high mechanical capacities.

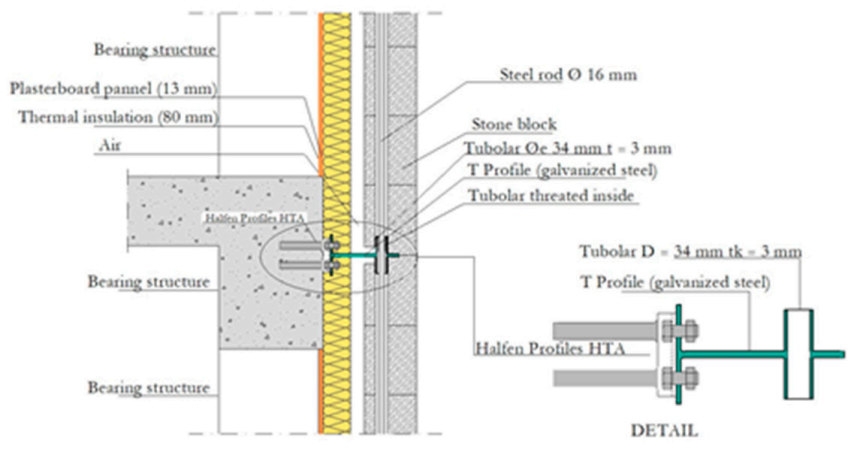

(a)

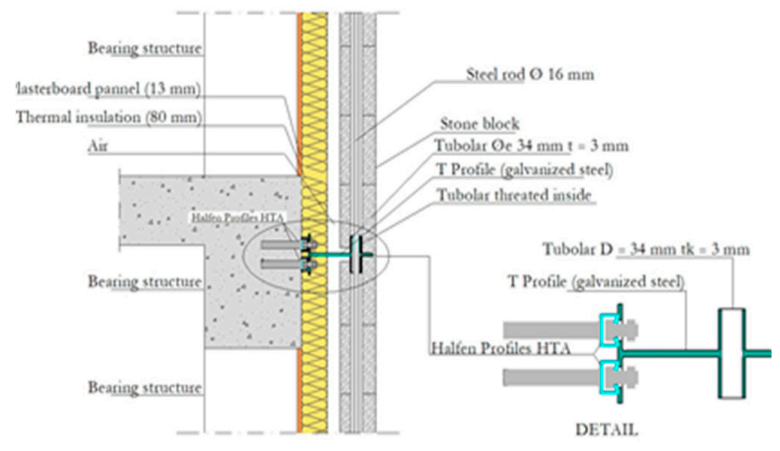

(b)

Figure 8. The connection between the existing structure and bracing panel (a) and panel (b).

For example, the Halfen profile type HTA-CE72/48 has a shear bearing capacity of more than $8 \mathrm{t}$ per dowel. The number of dowels, simplified to two (Figure 8a), can vary according to the results obtained from the structural checks.

The weight of the panels is totally transmitted to the foundation. The connection to the beams of the existing structure for panels that do not have the function of bracing, unlike in the previous case, is rendered in such a way that there is no transmission of stresses between the panel and the existing structure. In this case, the connection must allow for the independent displacement of the two elements parallel to the plane.

To this end, all elements that make up the connection mechanism remain unchanged, except for the two Halfen profiles that are arranged horizontally to allow for independent horizontal sliding

Global prestressing reinforcements, housed in the second hole, connect all panels from the foundations to the top end of the building.

At the top end of the last panel, the reinforcements are connected to the head blocks by means of galvanized steel plates $(80 \times 10 \mathrm{~mm})$ and a nut, M16 quality 8.8 , to which a specific tightening value is applied to give the necessary global prestressing (Figure $8 b$ ).

\section{Discussion}

The feasibility study of the seismic coat in natural prestressed stone shows that the new seismic coat made of natural stone assembled dry and pre-compressed has been designed to have a certain flexibility of use. It can be superimposed on the existing envelope and act as a second skin, or alternatively it can replace the existing envelope if the retrofit is more radical. 
Its reduced weight allows for the considerable reduction of the raw material used and the construction of panels through industrialized processes.

The two holes in the block are used for housing the reinforcements. The first hole is for the reinforcement required in the local prestressing of individual panels, which are industrially manufactured; the second hole is for reinforcement in order to obtain global prestressing in situ as connection between prefabricated panels (Figure 2).

For this purpose, the blocks placed at the ends of the panels are properly shaped to ensure continuity between the panels.

Unlike the reinforced concrete seismic coat already in production, the stone coat shows high durability because the thermal insulation placed inside is protected and does not require replacement every 25 years [16]. Moreover, the stone facade shows high durability of up to 175 years, without any maintenance [12].

The dry construction of the panel and its connections with the existing structure allow for the easy maintenance or replacement of some parts and the entire seismic coat.

In the case study, since it is a radical intervention involving the redesign of the facade, the concentrated bracing system through five bracing panels was adopted. These are symmetrically arranged in the plane in perimeter position in order to stiffen the existing structure in the two directions without creating torsional effects and in correspondence to closed panels without openings (Figure 5).

For the other panels, the feasibility study shows that with only one type of block and half-block, it is possible to industrially manufacture eight types of panels that allow for greater freedom in the architectural composition of the facade (Figure 4).

The connections with the existing structure at the floor beams were designed in such a way that the weight of the panels is transferred entirely to the ground through a reinforced concrete foundation curb (Figure 6). For the bracings, the connection with the structure allows for the transfer of horizontal actions, in the plane and out of plane (Figure 8a). For the others, the connection only prevents the movement out of the plane to avoid possible overturning (Figure 8b). These connections are all made with dry systems. This means that during maintenance or decommissioning of the coat, the panels are easily removed and all the material can be recycled without any additional work. The only element that cannot be removed is the reinforced concrete foundation curb along the perimeter of the building, which remains below the ground level.

This paper highlights how the results so far obtained from the feasibility study of a new environmentally sustainable natural stone seismic coat can perfectly meet expectations, also by describing its application to a case study.

The low environmental impact of the new coat affects all phases, as it allows low energy consumption both during construction-in terms of raw material, natural, local and embedded energy; in the life cycle of the building - in terms of energy for conditioning and maintenance; and at the end of life, allowing for the total recycling of components used.

The aspects of environmental sustainability and flexibility of use make the new natural stone seismic coat a component competitive with those already on the market and easily adaptable to meet the different needs in various retrofit interventions on the modern building heritage.

In the future, other case studies can be examined, which are typologically different in order to optimize the performance of the new seismic coat, with the aim of creating a prototype that can be marketed by companies in the industry.

The results obtained in the case of the seismic coat made of Etna lava stone can be applied to other types of local natural stone, recreating the genius loci of traditional buildings in different regions.

\section{Conclusions}

The research developed a new seismic coat that has environmentally sustainable qualities as an alternative to the existing reinforced concrete seismic coat, in addition to energy and seismic upgrading of existing buildings. 
In the case study consisting of a modern emerging building, the radical retrofit intervention with the use of the new seismic coat provided positive responses from different points of view.

The feasibility study of the seismic coat in natural prestressed stone has shown that the construction process can be carried out in all its phases through the dry assembly of the components. The advantages of the new seismic coat compared to those already on the market can be summarized as follows:

$\checkmark \quad$ Industrial prefabrication of individual panels prestressed in the factory;

$\checkmark \quad$ Easy maintenance because the panel can be easily removed;

$\checkmark$ Complete recovery of the material to be recycled;

$\checkmark \quad$ Far higher durability without requiring any maintenance;

$\checkmark$ Low environmental impact;

$\checkmark \quad$ Flexibility to adopt it as the only envelope or as a second skin;

$\checkmark$ Operation of installation on site extremely simplified;

$\checkmark \quad$ Very fast execution times;

$\checkmark \quad$ Use of unskilled labor;

$\checkmark \quad$ Aesthetic quality of the stone facade;

$\checkmark \quad$ Genius loci with the use of a material of local tradition.

Funding: This research received no external funding.

Institutional Review Board Statement: Not applicable.

Informed Consent Statement: Informed consent was obtained from all subjects involved in the study.

Data Availability Statement: Authorship.

Conflicts of Interest: The author declares no conflict of interest.

\section{References}

1. Bradley, P.E.; Kohler, N. Methodology for the survival analysis of urban building stocks. Build. Res. Inf. 2007, 35, 529-542. [CrossRef]

2. Thomsen, A.; Van der Flier, K. Obsolescence and the end of life phase of buildings. In Management and Innovation for a Sustainable Built Environment MISBE 2011, Proceedings of the CIB International Conference, Amsterdam, The Netherlands, 20-23 June 2011; TU Delft: Delft, The Netherlands, 2011.

3. Boeri, A.; Gabrielli, L.; Longo, D. Evaluation and feasibility study of retrofitting interventions on social housing in Italy. Procedia Eng. 2011, 21, 1161-1168. [CrossRef]

4. Turchini, G. New Research for the Restoration; Arketipo: Calenziano, Italy, 2011.

5. Lombardo, G. La Modernità del Basalto dell'Etna Innovazione e Sperimentazione; Il Lunario: Enna, Italy, 2004; ISBN 88-8181-059-X.

6. Lombardo, G. Built architecture with natural stone. Int. J. Hous. Sci. Appl. 2011, 35, 103-114.

7. Pertile, V.; Stella, A.; De Stefani, L.; Scotta, R. Miglioramento Sismico ed Energetico di Edifici in Muratura Mediante Cappotto Sismico: Seconda Campagna di Prove Sperimentali. Ingenio. 2020. Available online: https://www.ingenio-web.it/25301miglioramento-sismico-ed-energetico-di-edifici-mediante-geniale-cappotto-sismico-i-test-su-edifici-in-muratura (accessed on 9 December 2020).

8. Scotta, R.; De Stefani, L.; Stella, A.; Pertile, V. Miglioramento Sismico ed Energetico degli Edifici Esistenti Mediante “Cappotto Sismico": Prove Sperimentali ed Interpretazione dei Risultati. Ingenio. 2020. Available online: https://www.ingenio-web.it/2041 6-miglioramento-sismico-ed-energetico-degli-edifici-esistenti-mediante-cappotto-sismico (accessed on 9 December 2020).

9. Scotta, R.; Lucchetta, S. Adeguamento Sismico ed Efficientamento Energetico di una Scuola Mediante Cappotto Sismico: La Progettazione. Ingenio. 2020. Available online: https:/ /www.ingenio-web.it/26274-adeguamento-sismico-ed-efficientamentoenergetico-di-una-scuola-mediante-cappotto-sismico-la-progettazione (accessed on 9 December 2020).

10. Trovato, M.R.; Nocera, F.; Giuffrida, S. Life-cycle assessment and monetary measurements for the carbon footprint reduction of public buildings. Sustainability 2020, 12, 3460. [CrossRef]

11. Nocera, F.; Faro, A.L.; Costanzo, V.; Raciti, C. Daylight performance of classrooms in a mediterranean school heritage building. Sustainability 2018, 10, 3705. [CrossRef]

12. Molinari, C. Manutenzione in Edilizia; Franco Angeli: Milan, Italy, 1989; ISBN 8820430975.

13. Cicero, C.; Lombardo, G. Buildings envelopes and energy. J. Civ. Eng. Archit. 2011, 5, 986-995.

14. Hammond, G.; Jones, G. Inventory of Carbon E Energy (ICE); Version 2.0; Department of Mechanical Engineering, University of Bath: Bath, UK, 2011.

15. Paolini, R. Sistemi di Isolamento Termico a Cappotto; Arketipo: Calenziano, Italy, 2008; Volume 24, pp. $130-131$. 
16. Campioli, A.; Ferrari, S.; Lavagna, M. Il Comportamento Energetico-Ambientale di Involucri in Laterizio. Costr. Laterizio 2007, $120,58-65$.

17. Lavagna, M. Life Cycle Assessmente in Edilizia; Hoepli: Milan, Italy, 2008.

18. Lombardo, G. Architectural Vanguard Stone. Front. Archit. Res. 2012, 1, 244-252. [CrossRef]

19. Salehi, A.; Fayaz, R.; Bozorgi, M.; Asadi, S.; Costanzo, V.; Imani, N.; Nocera, F. Investigation of thermal comfort efficacy of solar chimneys under different climates and operation time periods. Energy Build. 2019, 205, 109528. [CrossRef]

20. Fernandez-Antolin, M.; del Río, J.M.; Costanzo, V.; Nocera, F.; Gonzalez-Lezcano, R. Passive design strategies for residential buildings in different Spanish climate zones. Sustainability 2019, 11, 4816. [CrossRef]

21. Gajda, J.; Van Geem, M. Energy Use in Residential Housing: A Comparison of Insulating Concrete Form and Wood Frame Walls; Portland Cement Association: Skokie, IL, USA, 2000.

22. Gajda, J. Energy Use of Single-Family Houses with Various Exterior Walls; Portland Cement Association: Skokie, IL, USA, 2001. 